\title{
Ubiquity of Rare Disorders in Malaysia: A Serious Thing to Look at
}

\author{
Tapash Rudra ${ }^{1 *}$, Hafizah Che Hasan ${ }^{2}$ and Kosheila Ramuni ${ }^{2}$ \\ ${ }^{1}$ Faculty of Science, Lincoln University College, Malaysia \\ ${ }^{2}$ Faculty of Nursing, Lincoln University College, Malaysia \\ *Corresponding author: Tapash Rudra, Faculty of Science, Department. of Biotechnology, Lincoln University College, Selangor, \\ Malaysia
}

\begin{abstract}
ARTICLE INFO
Received: 幽 August 28, 2019

Published: September 04, 2019

Citation: Tapash Rudra, Hafizah Che Hasan, Kosheila Ramuni. Ubiquity of Rare Disorders in Malaysia: A Serious Thing to Look at. Biomed J Sci \& Tech Res 21(1)-2019. BJSTR. MS.ID.003553.
\end{abstract}

Keywords: Rare Disorder; Genetic Factor; Environment; South East Asia; Malaysia

\begin{abstract}
Rare disorders are designated as orphan diseases as each one of them affects a tiny portion of the general population. However, with the span of more than 6000 varieties rare disorders affect a larger community overall. Duchene muscular dystrophy, Huntington's disease, blood disorders such as hemophilia, bone malfunctioning like brittle bone disease and achondroplasia are the most frequent types among the South East Asian population including Malaysia. Orphan diseases are primarily influenced by genetic attributes, along with the other associations like environmental factors, regular chemical exposure during gestation period/pregnancy, and infections respectively. Currently, the scenario of South East Asia as well as Malaysia is not looking promising regarding the strategic planning to counteract these upcoming manifestations. We should, therefore, make a thorough effort to propagate the information about such disorders among the civilians to achieve the best possible outcome. Researchers, health professionals, nonGovt. organizations (NGOs) and more importantly policy makers as well as politicians across the nation must be proactive to restrict the spread of such disorders.
\end{abstract}

\section{Introduction}

Whenever we talk about any disease, irrespective of its nature and manifestation, it's regardless to say that it won't portray any soothing aspect to it. Moreover, talking about "Rare disease", the trajectory and the perspectives would be far from common as it comprehends in our genetic organization. In spite of its rarity, genetic disease and chromosomal aberrations are quite frequent these days globally, off course, Malaysia is not an exception, too [1]. Duchene muscular dystrophy, Huntington's disease, blood disorders such as hemophilia, bone malfunctioning like brittle bone disease and achondroplasia are the most frequent among the South East Asian population including Malaysia. It is quite staggering that yearly around 16,500 out of 550,000 Malaysian babies perish due to congenital anomalies related to genetic disorders before they even cherish their first birthday [2]. It's worth mentioning that the most readily available remedy for the genetic diseases is to make the civilians aware by providing them proper information. In fact, very little information about these disorders are existing currently in Malaysia [3]. It is remarkable that in neighboring countries like Australia and Taiwan the overall frequency of genetic disease is less than $1 / 10,000$, whereas, in Malaysia the overall prevalence of the same manifestation is $1 / 4000$, according to the Malaysian Rare Disorder Society [3]. Furthermore, Malaysia is not volumetrically huge, and the nation comprises of several ethnic groups. This is the most crucial reason behind the accumulation of these diseases in the community.

\section{Prevalence of Rare Diseases}

According to World Health Organization (WHO), these disorders are designated as orphan disease as each one of them affects a very tiny bit of the general population. However, with the overall variety of more than 6000 types, rare diseases develop a large number of patients, sharing several clinical manifestations in common [4]. Genetic attributes (more than $80 \%$ ) are the principle reasons behind the development of such diseases. However, prolonged exposure to harmful environmental factors, regular chemical exposure during gestation period/pregnancy, and infections are also contributing towards the formation of these rare diseases. Around $9 \%$ of the general population across South East Asia are 
affected by orphan disorders [5]. The following table would give a brief idea where Malaysia is standing right now in terms of policy making towards the minimization of the rare diseases (Table 1).

Table 1: Strategic planning taken by countries to minimize the rare diseases across the globe.

\begin{tabular}{|c|c|c|}
\hline \multirow{7}{*}{ Policy and planning } & $\begin{array}{c}\text { Status } \\
\text { Decision to execute a } \\
\text { specific plan }\end{array}$ & $\begin{array}{c}\text { Countries } \\
\text { Organizing } \\
\text { stakeholder meeting } \\
\text { Vietnam }\end{array}$ \\
\cline { 2 - 3 } & $\begin{array}{c}\text { Policy/Plan submitted } \\
\text { to the concerned } \\
\text { ministry }\end{array}$ & $\begin{array}{c}\text { Thailand, Malaysia } \\
\text { Philippines, Australia } \\
\text { and Canada }\end{array}$ \\
\cline { 2 - 3 } & $\begin{array}{c}\text { National policy taken } \\
\text { care of in a routine } \\
\text { basis }\end{array}$ & South Korea \\
\cline { 2 - 3 } & $\begin{array}{c}\text { National plan } \\
\text { completely executed }\end{array}$ & France, Taiwan \\
\hline
\end{tabular}

Let us now have a look on the major reasons that develop the orphan disorders, especially in South East Asia including Malaysia:

a) Inability to identify the rare diseases due to lack of conclusive evidence

b) Lack of infra-structure and proper health care to counteract the orphan disorders

c) Unavailability of specific remedies

d) Lack of authentic genetic counselling centers/laboratories

e) Unavailability of good enough planning and subsequent execution

f) On the basis of the above-mentioned existing problems the following futuristic strategies should be taken into consideration:

g) Sizable authentic data should be collected from the population across Malaysia in relevance to the rare diseases.

h) Legislative policies should be robust enough to keep the rights intact of the individuals carrying orphan disorders.

i) General awareness should be of utmost importance. Both public and health care professionals must be aware about the basics of rare disorders.

\section{ISSN: 2574-1241}

DOI: 10.26717/BJSTR.2019.21.003553

Tapash Rudra. Biomed J Sci \& Tech Res

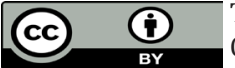

This work is licensed under Creative Commons Attribution 4.0 License

Submission Link: https://biomedres.us/submit-manuscript.php j) Prenatal as well as post-natal diagnosis and the respective treatment should be performed in a routine basis to minimize the overall frequency of the rare disease in the Malaysian population.

k) Newborn screening programme should be a regular feature to reduce the genetic and chromosomal anomalies in the population.

l) Specific laboratories with expert health care professionals must be established to specify the genetic disorders.

m) Policy makers as well as politicians should be proactive to approve and release the grants to escalate the treatment of such diseases by forming new rehabilitation centers.

n) Research should be prioritized to reveal more information in the field of rare disorders.

\section{Conclusion}

It is not a one man show to minimize the spreading of these uncommon diseases. The bottom line is, "Genetic disorders will remain in the population, and our task is to minimize the margin". Therefore, we must make sure that awareness among the civilians should be of highest degree. Researchers, health professionals, NGOs and more importantly policy makers as well as politicians across the nation must be proactive to restrict the spread of such disorders

\section{Acknowledgement}

None.

\section{Conflict of Interest}

No conflict of interest.

\section{References}

1. (2016) Ministry of Health Malaysia. National Strategic Plan for NonCommunicable Disease (NSP-NCD) 2016-2025.

2. (2015) Right Diagnosis from Health grades. Statistics by Country for Rare Diseases.

3. (2015) Pharmaceutical Research and Manufacturers of America (PhRMA). 2005-2015: A Decade of Innovation in Rare Diseases.

4. (2009) Eurordis. What is a Rare Disease?

5. (2015) Right Diagnosis from Healthgrades. Statistics by Country for Rare Diseases.

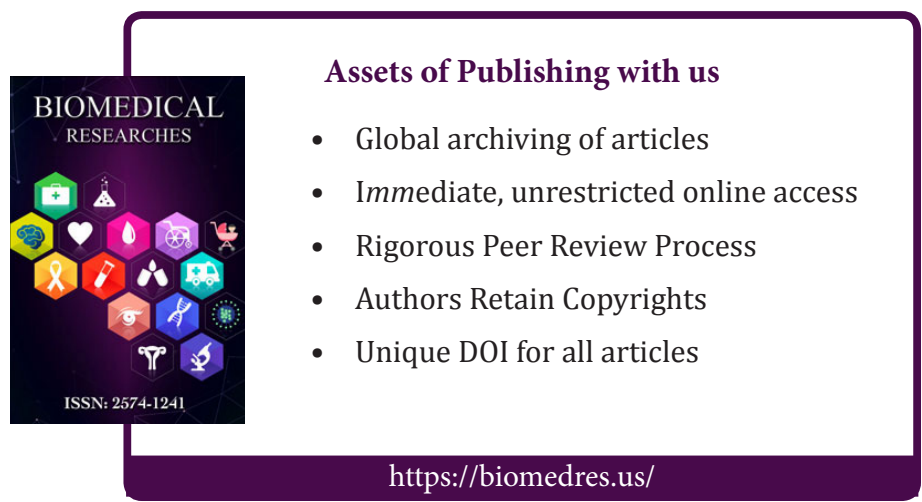

